\title{
Combined oral propranolol with intralesional injection of triamcinolone acetonide in treatment of infantile periocular hemangiomas
}

This article was published in the following Dove Press journal:

Clinical Ophthalmology

\section{Alahmady H Alsmman \\ Amr Mounir}

Department of Ophthalmology, Sohag Faculty of Medicine, Sohag University, Sohag, Egypt
Correspondence: Alahmady H Alsmman Department of Ophthalmology, Sohag Faculty of Medicine, Sohag University, Nahda Street, Sohag 82524, Egypt

$\mathrm{Tel}+20$ I I I II 02698

Email alahmady20@yahoo.com
Aim: To evaluate the clinical effectiveness of combined oral propranolol with intralesional injection of triamcinolone acetonide in the treatment of infantile periorbital capillary hemangioma.

Patients and Methods: This prospective interventional study included children diagnosed with periocular infantile hemangiomas in the proliferative phase with vision-threatening lesions. The children presented to the oculoplastic unit in Sohag University Hospital in the period between January 2016 and February 2017 and were treated with a combined intralesional injection of triamcinolone acetonide with oral propranolol, with a follow-up period of 6 months. Treatment response was evaluated according to the size of the tumor (horizontal diameter); additionally, complications of both treatment methods were recorded.

Results: This study included 33 infants: 21 females (64\%) and 12 males (36\%). The mean age at the time of injection was $4.9 \pm 2.6$ months. The study included three modes of treatment response: regression of the tumor, 28 patients (85\%); stabilization, three patients $(9 \%)$; and failure, two patients $(6 \%)$, which necessitated repeated intralesional injection of triamcinolone but with minimal response. Regarding complications, only one patient reported with subconjunctival hemorrhage during intralesional injection of steroids; there were no recorded cases of hypotension, bradycardia, or hypoglycemia during the course of oral propranolol treatment. After the end of the follow-up period, there were no reported cases of recurrent increase in the size of the regressed group of infantile hemangiomas with stable tumor size.

Conclusion: Combined oral propranolol with intralesional injection of triamcinolone acetonide is the effective method of treatment for infantile periorbital capillary hemangioma with minimal adverse effects.

Keywords: infantile periocular hemangioma, oral propranolol, intralesional injection, triamcinolone acetonide

\section{Introduction}

Infantile hemangiomas (IHs) is the most common, benign, self-limiting tumor of infancy, ${ }^{1-3}$ and infantile periocular capillary hemangioma is the most common, benign, vascular tumor of the eyelids and the orbits. ${ }^{4,5}$

The etiology of capillary hemangiomas is still unclear with the involvement of angiogenic and vasculogenic factors. ${ }^{6}$ The proliferation and involution phases of the tumor are controlled by multiple regulators that include molecular, cellular, and hormonal changes. ${ }^{7,8}$

Tumor involvement can be superficial, deep, or mixed. The majority of capillary hemangiomas enlarge over 6-9 months and then spontaneously involute over 2-10 years. 
The majority of capillary hemangiomas can be left untreated and allowed to follow their natural course. However, a significant group of hemangiomas are associated with morbidity in infancy and childhood. ${ }^{9}$

Focal infantile periocular capillary hemangioma is associated with a $46 \%-80 \%$ rate of severe complications. ${ }^{10}$ It can cause ptosis, displacement of the globe, and mechanical deformation of the immature sclera and cornea, leading to anisometropic astigmatism and refractive amblyopia. ${ }^{11,12}$ In severe cases, it can cause proptosis, exposure keratopathy, compressive optic neuropathy, and lid deformities. ${ }^{13,14}$

Although capillary hemangioma invariably involutes, treatment of periocular hemangiomas is often undertaken in an attempt to prevent permanent visual loss. ${ }^{15}$

Periorbital capillary hemangioma can be treated with oral, topical, or intralesional corticosteroids. ${ }^{16}$ Corticosteroids include a risk of serious ocular and systemic side effects. ${ }^{17}$

Intralesional injection may limit systemic exposures to corticosteroids, but complications include ophthalmic artery occlusion, retinal embolization, and central retinal artery occlusion. ${ }^{18-20}$

Propranolol at 2-3 $\mathrm{mg} / \mathrm{kg} / \mathrm{d}$ has been reported to be effcient at controlling the proliferation of capillary hemangioma. Improvement appears to be more rapid and greater with propranolol than with systemic steroids. ${ }^{21}$ Propranolol has become the main first-line systemic medical therapy for treatment of these tumors. ${ }^{22}$

The aim of our study was to prospectively evaluate the clinical effectiveness of combined oral propranolol with intralesional injection of triamcinolone acetonide in the treatment of infantile periorbital capillary hemangioma.

\section{Patients and methods}

This was a prospective interventional study that included children diagnosed as having periocular IHs and who presented to the oculoplastic unit in Sohag University Hospital in the period between January 2016 and February 2017.

All patients were subjected to detailed ophthalmic examination before the start of treatment which included evaluation of ptosis and ocular position, measurement of visual acuity with age-appropriate methods (quality of fixation response in infants), orthoptic assessment, dilated fundus examination, and cycloplegic refraction.

The extent of periorbital hemangioma and its complications such as ptosis, proptosis, strabismus, astigmatism, and amblyopia was evaluated. Most of the children were also subjected to magnetic resonance imaging with contrast material to determine if there was a periocular extension of the lesion. A pediatric evaluation was done for all cases to exclude systemic anomalies, neuroimaging to exclude intracranial abnormalities, abdominal ultrasonography to exclude visceral involvement, and echocardiography by a pediatric cardiologist.

Patients who were treated previously with both systemic and intralesional corticosteroids were excluded, as also patients with intraorbital IHs which cannot be treated with intralesional therapy.

The ethical committee that approved this study was the Sohag faculty of Medicine, Sohag University, and the study was carried out according to the Declaration of Helsinki. The parents of all study patients gave their written informed consent for the treatment all cases and for the images to be published in this study.

All patients received combined intralesional injection of triamcinolone acetonide with oral propranolol with a follow-up period of 6 months.

Intralesional injection triamcinolone acetonide $40 \mathrm{mg} / \mathrm{mL}$ (Kenalog; Bristol-Myers Squibb SRL, Anagni, Italy) was done initially for all patients. Injections were performed using a 1-cc syringe and a 30-gauge needle. Injections were performed under general anesthesia. The total dose of intralesional steroid varied from 0.1 to $1 \mathrm{cc}$ according to the tumor size. The needle position was checked both visually and by palpation. Vascular injection was avoided by checking blood aspirate in the needle. Hemostasis was maintained by pressure on the injection site. All patients received single injection; only two received two injections because of poor response.

All treatments were administered by the same surgeon (Alahmady $\mathrm{H}$ Alsmman). Intraocular pressure monitoring and funduscopic monitoring were done during injection. After intralesional injection, all patients received oral propranolol at a dose of $1 \mathrm{mg} / \mathrm{kg} / \mathrm{d}$ (Inderal $20 \mathrm{mg} / 5 \mathrm{~mL}$ ) in three divided doses.

Propranolol syrup was prepared from tablets. All children were admitted in the pediatric department at the Sohag Faculty of Medicine in order to monitor pulse rate and blood pressure every half an hour for the first 4 hours. If the child tolerated the treatment with no side effects, therapy was continued in an outpatient clinic. Blood glucose level was also measured in a periodic manner during therapy.

The dose was increased gradually to $2 \mathrm{mg} / \mathrm{kg} / \mathrm{d}$ in three divided doses if there were no adverse effects from the initial therapy. The patients were maintained on oral propranolol thereafter. Patients were followed up on a weekly basis for the first month, then every 2 weeks in the second month, and finally at 4 weekly intervals for a period of 2 months. Then, a gradual tapering to $1 \mathrm{mg} / \mathrm{kg}$ body weight in the sixth month was done following which it was stopped. Follow-up for 
tumor regression was done at monthly intervals for 6 months after starting oral treatment of propranolol.

Treatment response was evaluated by the size of the tumor (horizontal diameter) and the clinical response that was classified into three categories: regression (tumor decreased in size), stabilization (the tumor stopped to grow), and failure (tumor continued to enlarge in spite of combined treatment). Also, complications of both treatment methods were recorded.

\section{Results}

This study included 33 infants - 21 females (64\%) and 12 males (36\%). The mean age at the time of injection was $4.9 \pm 2.6$ months. According to the size of the tumor, they were classified into three categories: small $(<3 \mathrm{~cm})$, medium $(>3 \mathrm{~cm}$ and $<8 \mathrm{~cm})$, and large $(>8 \mathrm{~cm})$. Table 1 summarizes the number of each group according to the size.

A total of 19 patients showed upper lid involvement and 14 showed lower lid involvement. Five patients presented with complications, four with mechanical ptosis, and one with amblyopia. Table 2 summarizes the clinical characteristics of all patients.

The study included three modes of treatment response: regression of the tumor occurred in 28 patients $(85 \%)$, (Figures 1-3) stabilization occurred in three of them (9\%), and failure in two $(6 \%)$, which necessitated repeated intralesional injection of triamcinolone but with minimal response. Table 3 summarizes the number of tumors according to regression.

Regarding complications, only one patient reported with subconjunctival hemorrhage during intralesional injection of steroids; there were no recorded cases of hypotension, bradycardia, or hypoglycemia during the course of oral propranolol treatment.

After the end of the follow up period there were no reported cases of recurrent increase in the size of the regressed group of IHs with stable tumor size.

\section{Discussion}

Infantile hemangiomas (IHs) are a benign vascular tumor, which shows rapid growth after birth and usually regresses spontaneously. ${ }^{23}$ Periorbital lesions carry the risk of vision affection through occlusion of the pupil, compression of the

Table I Number of each group according to the size

\begin{tabular}{lll}
\hline Classification & Size & Number of cases \\
\hline Small & $<3 \mathrm{~cm}$ & 18 \\
Medium & $>3 \mathrm{~cm}$ and $<8 \mathrm{~cm}$ & 13 \\
Large & $>8 \mathrm{~cm}$ & 2 \\
\hline
\end{tabular}

Table 2 Clinical characteristics of all patients

\begin{tabular}{ll}
\hline Laterality & Right eye: 13 \\
& Left eye: 20 \\
Upper or lower lid & Upper lid: 19 \\
& Lower lid: 14 \\
Complications & $4:$ mechanical ptosis \\
& I: amblyopia \\
\hline
\end{tabular}

globe, and expansion in the retrobulbar space, which leads to amblyopia, strabismus, astigmatism, and optic nerve atrophy. ${ }^{24,25}$

Many modalities of therapies have been described, including intralesional steroid injection, systemic steroids, 16 topical or intralesional injections of nonselective beta blocker, and oral nonselective beta blocker. ${ }^{26}$

Because of the systemic risks of long-term oral steroid use, intralesional corticosteroid injection is more commonly used. This modality has the advantage of a high dose of drug being directly injected into the tumor, thus reducing the liability of systemic absorption. ${ }^{27}$

Systemic propranolol is a new treatment modality therapy introduced by Leaute-Labreze in $2008 .^{28}$ Because of its long history of use in the infant population and its relatively low risk, some recommend systemic propranolol as a first-line
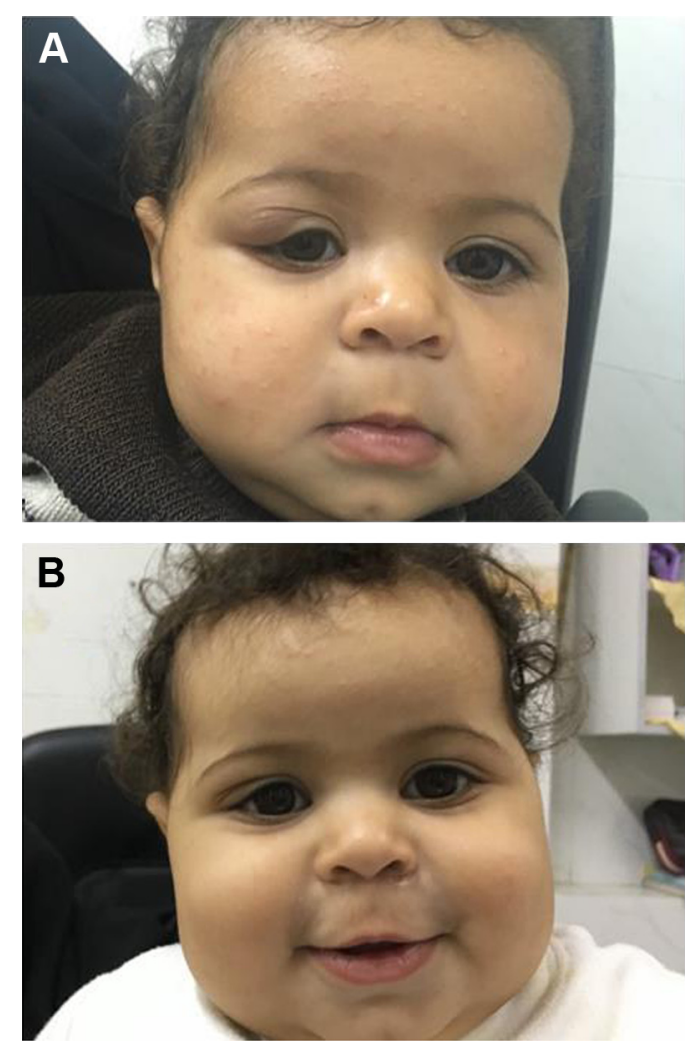

Figure I Infant, 6 months of age, with right-eye hemangioma.

Notes: Upper lid hemangioma (A) before treatment and (B) at 3 months posttreatment. 

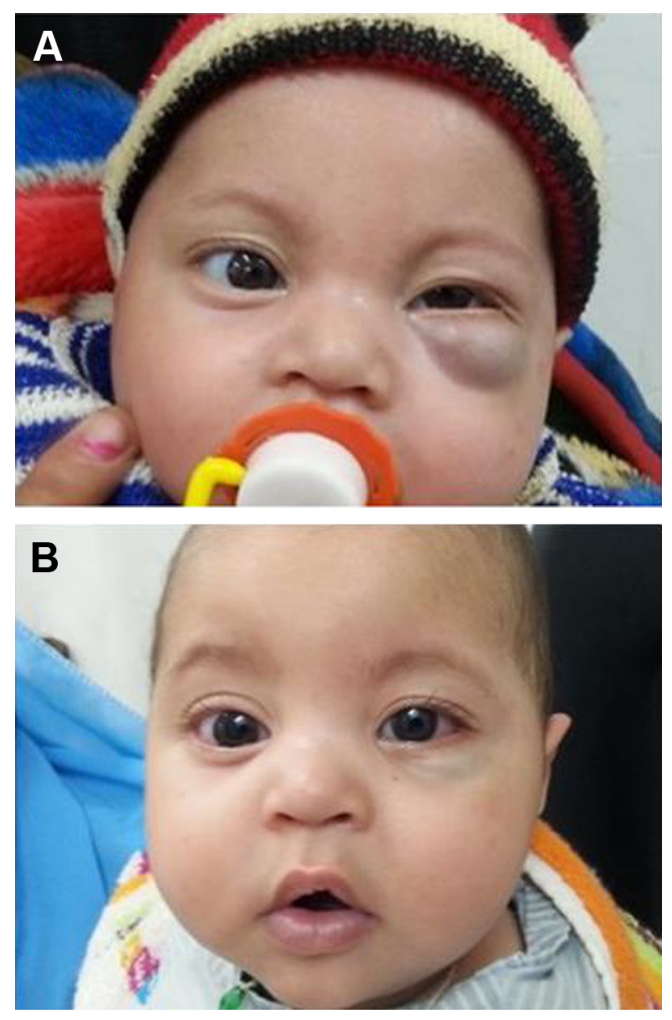

Figure 2 Infant, 2 months of age, with left-eye hemangioma.

Notes: Lower lid hemangioma (A) before treatment and (B) at 2 months posttreatment.
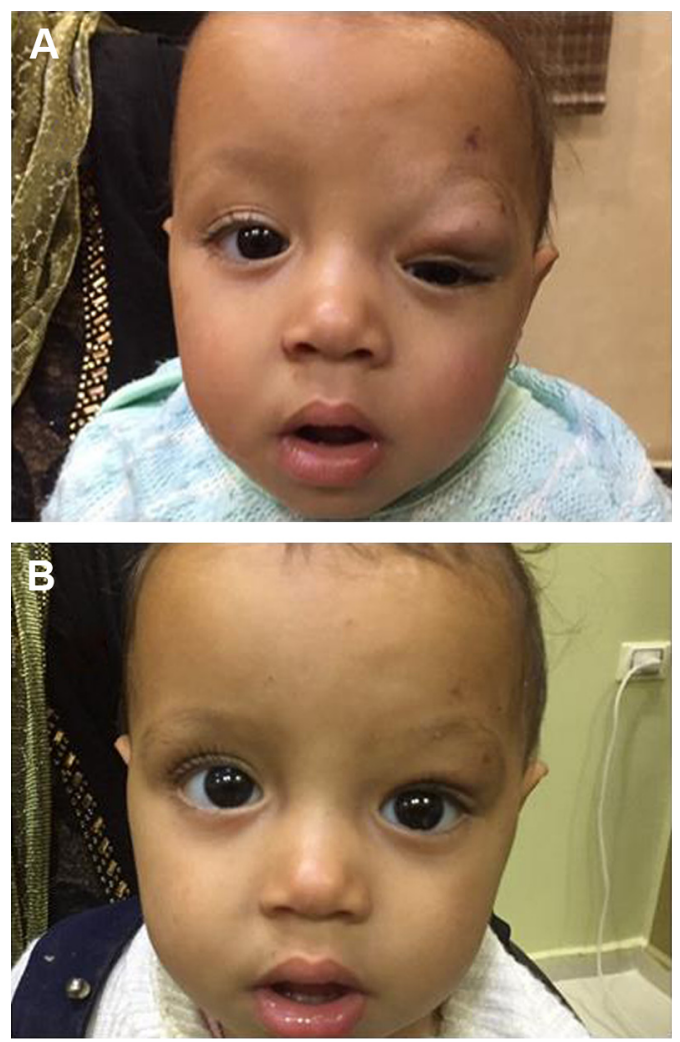

Figure 3 Infant, 3 months of age, with left-eye hemangioma.

Notes: Upper lid hemangioma (A) before treatment and (B) at 4 months posttreatment.
Table 3 Number of tumors according to regression

\begin{tabular}{ll}
\hline $\begin{array}{l}\text { Tumor response } \\
\text { in regressed cases (\%) }\end{array}$ & $\begin{array}{l}\text { Number } \\
\text { of cases }\end{array}$ \\
\hline $0-25$ & $\mathrm{I}$ \\
$25-50$ & 6 \\
$50-75$ & 14 \\
$75-100$ & 7 \\
\hline
\end{tabular}

therapy for periocular and laryngeal hemangiomas that require treatment. ${ }^{29}$

Combined treatment of $\mathrm{IOH}$ has been reported in many studies. ${ }^{30,31}$ In our study, we evaluated the effectiveness of combined oral propranolol with an intralesional injection of triamcinolone acetonide in the treatment of infantile periorbital capillary hemangioma. The aim of this combined therapy to get the benefit of two different mechanisms of action with lessening side effects of both drugs.

Our study included 33 infants with IOH in the proliferative phase with vision-threatening lesions. We started with a single intralesional injection of triamcinolone acetonide to avoid complications of repeated injections such as eyelid hypopigmentation, linear subcutaneous fat atrophy, eyelid necrosis, and periocular calcification..$^{32-34}$

All patients received oral propranolol after injection with heart rate, blood pressure, and systemic glucose level monitoring during therapy period.

A total of $85 \%$ of patients showed regression in the tumor size with a maintained effect to the end of the follow-up period. No change in the tumor size was reported in $9 \%$ of the patients, while $6 \%$ showed an increase in tumor size. Injections of triamcinolone were repeated for these patients, but there was no improvement in their condition. Surgical excision, which is the last option that is reserved for large hemangiomas that are not responsive to conservative treatments, but which endangers the infant's vision, ${ }^{18}$ was thought of for these patients.

No complications were reported from oral propranolol therapy in this study, because its safety profile is well established when given to appropriate patients with good monitoring. ${ }^{30}$

One patient reported with subconjunctival hemorrhage caused by a complication arising out of the intralesional steroid therapy. Apart from this, there were no other complications especially because most tumors were injected by one single injection.

\section{Conclusion}

Combined oral propranolol with intralesional injection of triamcinolone acetonide in infantile periorbital capillary 
hemangioma is an effective and safe method of treatment with minimal adverse effects. However, a comparative study with other modalities with a longer follow-up period is recommended.

\section{Disclosure}

The authors report no conflicts of interest in this work.

\section{References}

1. Bruckner AL, Frieden IJ. Hemangiomas of infancy. J Am Acad Dermatol. 2003;48(4):477-493.

2. Boye E, Olsen BR. Signaling mechanisms in infantile hemangioma. Curr Opin Hematol. 2009;16(3):202-208.

3. Chang EI, Chang EI, Thangarajah H, Hamou C, Gurtner GC. Hypoxia, hormones, and endothelial progenitor cells in hemangioma. Lymphat Res Biol. 2007;5(4):237-243.

4. Tavakoli M, Yadegari S, Mosallaei M, Aletaha M, Salour H, Lee WW. Infantile periocular hemangioma. J Ophthalmic Vis Res. 2017;12(2): 205-211.

5. Eivazi B, Ardelean M, Bäumler W, et al. Update on hemangiomas and vascular malformations of the head and neck. Eur Arch Otorhinolaryngol. 2009;266(2):187-197.

6. Ritter MR, Butschek RA, Friedlander M, Friedlander SF. Pathogenesis of infantile haemangioma: new molecular and cellular insights. Expert Rev Mol Med. 2007;9:1-19.

7. Sommers Smith SK, Smith DM. Beta blockade induces apoptosis in cultured capillary endothelial cells. In Vitro Cell Dev Biol Anim. 2002; 38:298-304

8. Razon MJ, Kraling BM, Mulliken JB, Bischoff J. Increased apoptosis coincides with onset of involution in infantile hemangioma Microcirculation. 1998;5:189-195.

9. Frieden IJ, Haggstrom AN, Drolet BA, et al. Infantile hemangiomas: current knowledge, future directions. Proceedings of a research workshop on infantile hemangiomas, April 7-9, 2005, Bethesda, Maryland, USA. Pediatr Dermatol. 2005;22:383-406.

10. Robb RM. Refractive errors associated with hemangiomas of the eyelids and orbit in infancy. Am J Ophthalmol. 1977;83:52-58.

11. Schwartz SR, Blei F, Ceisler E, et al. Risk factors for amblyopia in children with capillary hemangiomas of the eyelids and orbit. JAAPOS. 2006;10:262-268.

12. Weiss AH, Kelly JP. Reappraisal of astigmatism induced by periocular capillary haemangioma and treatment with intralesional corticosteroid injection. Ophthalmology. 2008;115:390-397.

13. Mitchell DE, Freeman RD, Millodot M, Haegerstrom G. Meridional amblyopia: evidence for modification of the human visual system by early visual experience. Vision Res. 1973;13:535-558.

14. Levi M, Schwartz S, Blei F, et al. Surgical treatment of capillary hemangiomas causing amblyopia. J AAPOS. 2007;11:230-234.

15. Ranchod TM, Frieden IJ, Fredrick DR. Corticosteroid treatment of periorbital haemangioma of infancy: a review of the evidence. $\mathrm{Br} J$ Ophthalmol. 2005;89(9):1134-1138.

Clinical Ophthalmology

\section{Publish your work in this journal}

Clinical Ophthalmology is an international, peer-reviewed journal covering all subspecialties within ophthalmology. Key topics include: Optometry; Visual science; Pharmacology and drug therapy in eye diseases; Basic Sciences; Primary and Secondary eye care; Patient Safety and Quality of Care Improvements. This journal is indexed on
16. Steahly LP, Almquist HT. Steroid treatment of an orbital or periocular hemangioma. J Pediatr Ophthalmol. 1977;14:35-37.

17. Shorr N, Seiff SR. Central retinal artery occlusion associated with periocular corticosteroid injection for juvenile hemangioma. Ophthalmic Surg. 1986;17:229-231.

18. Walker RS, Custer PL, Nerad JA. Surgical excision of periorbital capillary hemangiomas. Ophthalmology. 1994;101:1333-1340.

19. Egbert JE, Schwartz GS, Walsh AW. Diagnosis and treatment of an ophthalmic artery occlusion during an intralesional injection of corticosteroid into an eyelid capillary hemangioma. Am J Ophthalmol. 1996; 121:638-642.

20. Kushner BJ, Lemke BN. Bilateral retinal embolization associated with intralesional corticosteroid injection for capillary hemangioma of infancy. J Pediatr Ophthalmol Strabismus. 1993;30:397-399.

21. Manunza F, Syed S, Laguda B, et al. Propranolol for complicated infantile haemangiomas: a case series of 30 infants. Br J Dermatol. 2010;162: 466-468.

22. Darrow DH, Greene AK, Mancini AJ, et al. Diagnosis and management of infantile hemangioma. Pediatrics. 2015;136(4):e1060-e1104.

23. Mendiratta V, Jabeen M. Infantile hemangioma: an update. Indian $J$ Dermatol Venerol Leprol. 2010;76:469-475.

24. Thomson HG, Ward CM, Crawford JS, Stigmar G. Hemangiomas of the eyelid: visual complications and prophylactic concepts. Plast Reconstr Surg. 1979;63:641-647.

25. Goldberg NS, Rosanova MA. Periorbital hemangiomas. Dermatol Clin 1979;10:653-661.

26. Bagazgoitia L, Torrelo A, Gutiérrez JC, et al. Propranolol for infantile hemangiomas. Pediatr Dermatol. 2011;28(2):108-114.

27. Bang GM, Setabutr P. Periocular capillary hemangiomas: indications and options for treatment. Middle East Afr J Ophthalmol. 2010; 17(2):121-128.

28. Sans V, de la Roque ED, Berge J, et al. Propranolol for severe infantile hemangiomas: follow-up report. Pediatrics. 2009;124(3):e423-e431.

29. Denoyelle F, Leboulanger N, Enjolras O, et al. Role of propranolol in the therapeutic strategy of infantile laryngotracheal hemangioma. Int J Pediatr Otorhinolaryngol. 2009;73(8):1168-1172.

30. Koay AC, Choo MM, Nathan AM, et al. Combined low-dose oral propranolol and oral prednisolone as first-line treatment in periocular infantile hemangiomas. J Ocul Pharmacol Ther. 2011;27(3):309-311.

31. Wong MYY, Yau GSK, Lee JWY, et al. Management of a large periocular infantile hemangioma with oral propranolol and surgical excision: A Case Report and Review. J Pregnancy Child Health. 2014;1:103.

32. Droste PJ, Ellis FD, Sondhi N, et al. Linear subcutaneous fat atrophy after corticosteroid injection of periocular hemangiomas. Am J Ophthalmol. 1988;105:65-69.

33. Dyment PG. Local atrophy following triamcinolone injection. Pediatrics. 1970;46:136-137.

34. Sutula FC, Glover AT. Eyelid necrosis following intralesional corticosteroid injection for capillary hemangioma. Ophthalmic Surg. 1987; $18: 103-105$

\section{Dovepress}

PubMed Central and CAS, and is the official journal of The Society of Clinical Ophthalmology (SCO). The manuscript management system is completely online and includes a very quick and fair peer-review system, which is all easy to use. Visit http://www.dovepress.com/ testimonials.php to read real quotes from published authors. 